\title{
Validated Stability Indicating Chromatographic Method for the Simultaneous Estimation of Camylofin with NSAID Drugs and a New Approach of Method Transfer from Classical HPLC to a Modern UPLC Instrument
}

\author{
Sheetal Makwana, ${ }^{1,2}$ Madhavi Patel, ${ }^{1}$ Devang Prajapati, ${ }^{1}$ Chandni Shingala, ${ }^{1}$ \\ Jatin Upadhyay, ${ }^{2}$ and Anamik Shah ${ }^{1}$ \\ ${ }^{1}$ Center of Excellence in Drug Discovery, NFDD Complex, Department of Chemistry, Saurashtra University, Rajkot, \\ Gujarat 360005, India \\ ${ }^{2}$ Matushri Virbaima Mahila Science \& Home Science College, Rajkot, India
}

Correspondence should be addressed to Anamik Shah; anamik_shah@hotmail.com

Received 27 April 2016; Revised 13 September 2016; Accepted 19 September 2016

Academic Editor: Susana Casal

\begin{abstract}
Copyright (C) 2016 Sheetal Makwana et al. This is an open access article distributed under the Creative Commons Attribution License, which permits unrestricted use, distribution, and reproduction in any medium, provided the original work is properly cited.

The presented work describes the method development of simultaneous determination of camylofin dihydrochloride (CMF), diclofenac potassium (DCF), and Paracetamol (PCM) using reversed phase high performance liquid chromatography (HPLC-UV) and the method was further transferred to a new generation instrument, ultraperformance liquid chromatography (UPLC-PDA). The detailed validation was carried out for the combination tablet formulation of CMF and DCF by UPLC-PDA. From the method development study, Acquity UPLC HSS C18 $(2.1 \times 50 \mathrm{~mm}, 1.8 \mu \mathrm{m})$ was finally selected for validation. The satisfactory results were observed for peak shape, retention time, and resolution with a mobile phase of $20 \mathrm{mM}$ ammonium acetate buffer ( $\mathrm{pH} 3.0$ with dilute orthophosphoric acid) : methanol $(33: 67 \mathrm{v} / \mathrm{v})$. The isocratic elution of mobile phase was carried out at a flow rate of $0.250 \mathrm{~mL} / \mathrm{min}$ and detection at $220 \mathrm{~nm}$. Both drugs were efficiently separated out in less than $3.5 \mathrm{~min}$ with 1.1 and $3.2 \mathrm{~min}$ of retention time of the CMF and DCF with 11.87 of resolution. The linearity was obtained in the $20.0-80.0 \mu \mathrm{g} / \mathrm{mL}$ range of concentration with 0.9998 of correlation coefficients for the substances. The method was analyzed for specificity with detailed force degradation study, which is a simple, precise, and accurate method, as per the International Conference on Harmonization (ICH) guidelines.
\end{abstract}

\section{Introduction}

Camylofin dihydrochloride (CMF) is an antimuscarinic drug which is used as an antispasmodic drug. Chemically, it is known as a 3-methylbutyl 2-(2-diethyl-aminoethylamino)2-phenyl-acetate hydrochloride $[1,2]$. Diclofenac potassium (DCF) is a nonsteroidal anti-inflammatory drug (NSAID). It is used as an anti-inflammatory, analgesic, and antipyretic drug [3-5] and also relieves pain of rheumatic and nonrheumatic kinds of diseases [6] and chronic pain associated with cancer [7]. Paracetamol (PCM) is chemically known as an $\mathrm{N}$-(4-hydroxyphenyl) acetamide [8] and very well known as an acetaminophen [9]. Generally it is an analgesic and antipyretic class of drug, used for the treatment of fever and pain $[10,11]$. The chemical structure of camylofin dihydrochloride, diclofenac potassium, and Paracetamol is given in Figure 1.

On the basis of literature review, there are many methods available for the determination of CMF, DCF, and PCM in single as well as combined dosage with other drugs by GC, HPLC, HPTLC, and UV [12-17] but there is no isocratic RPUPLC method for the determination of CMF-DCF and CMFPCM in combination dosage form or tablet, but the proposed developed method by HPLC is novel. 


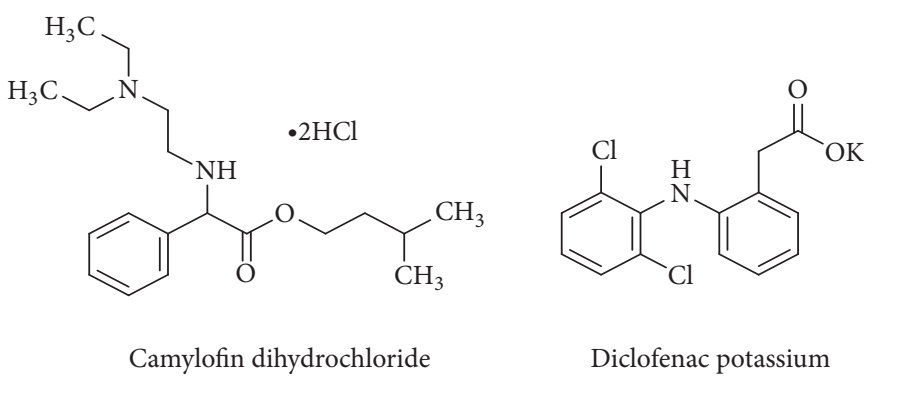

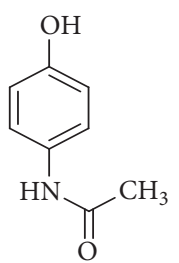

Paracetamol

Figure 1: Chemical structure of CMF, DCF, and PCM.

\section{Experimental}

2.1. Materials and Methods. Working standards of CMF and DCF were purchased from Sigma Aldrich and Paracetamol was gifted by Hetero drugs Limited (Hyderabad, India) and combination tablet of CMF-DCF, Anaspas tablet (CMF $50 \mathrm{mg}$ : DCF $50 \mathrm{mg}$ ), and Anafortan (CMF $25 \mathrm{mg}: \mathrm{PCM}$ $300 \mathrm{mg}$ ) was purchased from the market. Analytical-grade hydrochloric acid, hydrogen peroxide $(30 \% \mathrm{v} / \mathrm{v})$, and sodium hydroxide pellets were from Ranbaxy Fine Chemicals (New Delhi, India). Methanol, orthophosphoric acid, and HPLC grade was from Merck, Ammonium acetate was from Spectrochem Pvt. Ltd. (Mumbai, India), and HPLC grade water was prepared using Milli-Q Elix-3 water purification system. Nylon syringe filters $(0.22 \mu \mathrm{m})$ were purchased from Millex$\mathrm{HN}$, Millipore (Mumbai, India).

2.2. Instrumentation. The liquid chromatography method was developed by Waters HPLC equipment with TM 600 quaternary pump, waters $2489 \mathrm{UV} / \mathrm{Vis}$ detector, waters 600 controller, waters in line degasser $\mathrm{AF}$, and manual injector with $20 \mu \mathrm{L}$ loop. The equipment was connected to a multiinstrument data, acquisition and data, processing system (Empower software 2.0)

The final validation work was carried out by the Waters Acquity UPLC chromatographic system (Waters, Milford, MA, USA). This system consists of a binary solvent manager (BSM), photodiode array detector (PDA), sample manager (SM), and column oven connected to a multi-instrument data acquisition and processing system (Empower version 2.1). Sartorius CPA2P analytical microbalance (Gottingen, Germany) and an ultrasonic bath SONICA Spinco were used for degassing purpose from Spincotech Pvt. Ltd. (Mumbai, India). Milli-Q Elix-3 water purification system (Millipore, Milford, USA) was used as an HPLC grade water source. The $\mathrm{pH}$ of buffer mobile phase was adjusted by $827 \mathrm{pH}$ lab of 5.857.0011 program version, Metrohm swiss mode instrument, from Herisau, Switzerland.

2.3. Mobile Phase. To prepare $20 \mathrm{mM}$ ammonium acetate buffer, $1.5416 \mathrm{gm}$ was weighed and dissolved and used to make up to 1 liter of HPLC grade water and $\mathrm{pH}$ was adjusted to 3.0 with diluted orthophosphoric acid. It was filtered by $0.22 \mu \mathrm{m}$ filter paper with Millipore vacuum filter assembly and sonicated with an ultrasonic bath.
The final composition of mobile phase is (33: $67 \mathrm{v} / \mathrm{v})$ using $20 \mathrm{mM}$ ammonium acetate buffer ( $\mathrm{pH}$ 3.0) and methanol.

2.4. Preparation of Diluents. Mobile phase was used as diluents in proportion of $50: 50 \mathrm{v} / \mathrm{v}$.

2.5. Preparation of Standard Solution. Standard stock solutions $(500 \mu \mathrm{g} / \mathrm{mL})$ of CMF, DCF, and PCM were prepared by transferring accurately weighed $12.5 \mathrm{mg}$ of working standards into a $25 \mathrm{~mL}$ of volumetric flask, respectively. The stock solution of each drug was prepared in methanol. Standard solutions were prepared by accurately transferring $1.0 \mathrm{~mL}$ of stock solution into $10 \mathrm{~mL}$ of volumetric flask to furnish the same final concentration of CMF, DCF, and PCM $(50 \mu \mathrm{g} / \mathrm{mL})$ and diluted with mobile phase up to the mark. The standard solutions had been prepared for the same concentration of CMF and DCF $(50: 50 \mu \mathrm{g} / \mathrm{mL})$ and for the combination of CMF and PCM to furnish final concentration $25 \mu \mathrm{g} / \mathrm{mL}: 300 \mu \mathrm{g} / \mathrm{mL}$, respectively, by appropriate dilution using reference standard.

2.6. Preparation of Sample Solution. Around 20 tablets were taken then crushed and powdered. From that, the equivalent weight was taken to make the final stock concentration of CMF and DCF $(500 \mu \mathrm{g} / \mathrm{mL})$ for both of the drugs. After sonication and filtration of stock solution with $0.22 \mu \mathrm{m}$ nylon syringe filter, the sample solutions were prepared by accurately transferring $1.0 \mathrm{~mL}$ from the stock solution and further diluted with mobile phase to get final concentration $(50 \mu \mathrm{g} / \mathrm{mL})$ for each drug. Similar to the preparation of standard solution, the sample solution was prepared for the concentration as per CMF : DCF $50: 50 \mu \mathrm{g} / \mathrm{mL}$ and CMF:PCM 25:300 $\mu \mathrm{g} / \mathrm{mL}$ by final dilution using tablet.

2.7. Chromatographic Condition. Chromatographic analysis was carried out on HSS C18 $(2.1 \times 50 \mathrm{~mm}, 1.8 \mu \mathrm{m})$ and Sunfire C18 $(4.6 \times 150 \mathrm{~mm}, 5 \mu \mathrm{m})$ column at $0.250 \mathrm{~mL} / \mathrm{min}$ and $1.0 \mathrm{~mL} / \mathrm{min}$ for UPLC and HPLC, respectively. The mobile phase consists of $20 \mathrm{mM}$ ammonium acetate buffer $(\mathrm{pH} 3.0)$ : methanol in the ratio of $33: 67 \mathrm{v} / \mathrm{v}$ and was used throughout the analysis; temperature was $30^{\circ} \mathrm{C}$ at $220 \mathrm{~nm}$ for both of the instruments. 


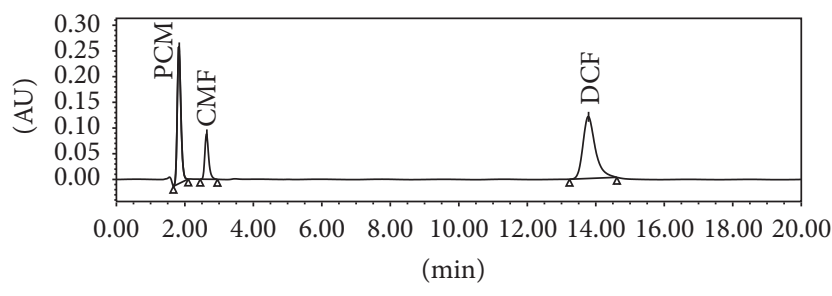

Figure 2: Chromatogram of PCM, CMF, and DCF by HPLC.

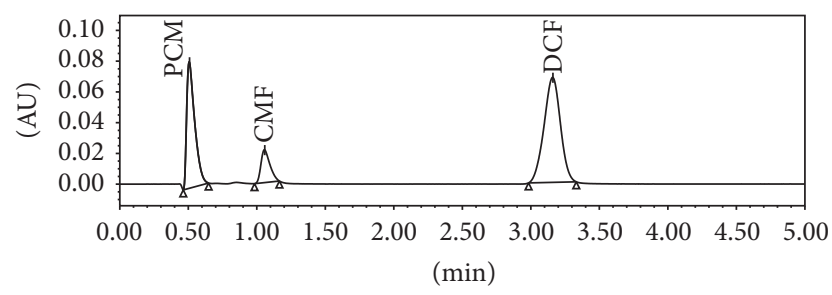

Figure 3: Chromatogram of PCM, CMF, and DCF by UPLC.

\section{Results and Discussion}

3.1. Method Development. On the basis of physical and chemical nature of the compounds, the chromatographic parameter selection is carried out. There were various experimental trials done, such as mobile phase with different $\mathrm{pH}$, composition with organic solvents, flow rate, column temperature, and wavelength of detection. Acetonitrile was taken for initial trials as an organic constituent of mobile phase, but peak shape was not so good. Then with $20 \mathrm{mM}$ ammonium acetate and methanol different trials were practically observed, which give better peak shape than acetonitrile. After that, some additional changes were done, such as $\mathrm{pH}$ changes of mobile phase and diluents, to reduce the peak tailing. Finally the chromatographic method was optimized using HPLC and validated as per ICH guidelines [18], USP [19], and AOAC international [20], using UPLC with mobile phase of $20 \mathrm{mM}$ ammonium acetate $(3.0 \mathrm{pH}$ with diluted orthophosphoric acid) and methanol in the proportion of $33: 67 \mathrm{~mL}$ v/v. Furthermore, the mobile phase was used as diluents in same ratio of $50: 50 \mathrm{~mL}$ v/v which gives better peak shape with good symmetry, resolution, and retention time in validation as well as for stress degradation study. The chromatograph of mixture of three drugs obtained from HPLC and UPLC are given in Figures 2 and 3, respectively. The three-dimensional chromatogram of CMF, DCF, and PCM using UPLC is given in Figure 4.

\subsection{Detailed Method Validation for CMF and DCF}

3.2.1. Solution Stability. Stability study of solution was performed by comparing the freshly prepared standard and sample solutions with aged solution at $3-5^{\circ} \mathrm{C}$ and at room temperature with different interval of time from initial to $48 \mathrm{~h}$. After each $6 \mathrm{~h}$ interval from initial the solution was tested and it is observed that, at $3-5^{\circ} \mathrm{C}$ of temperature, the solution is stable for $48 \mathrm{~h}$ but, at room temperature, it is stable for $24 \mathrm{~h}$. The $\%$ RSD value and \% assay were within the

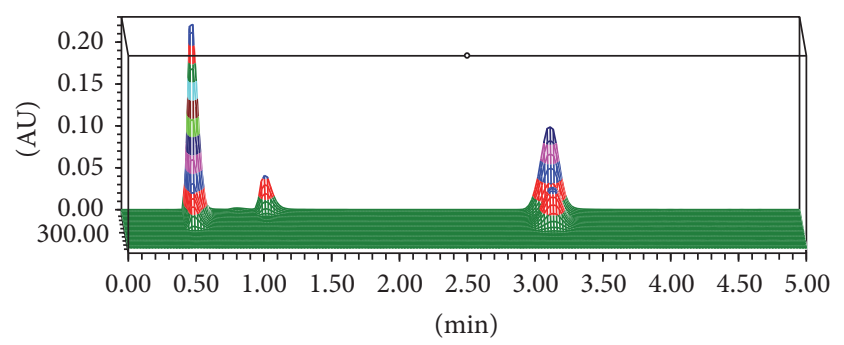

FIGURE 4: Three-dimensional chromatogram of PCM, CMF and DCF.

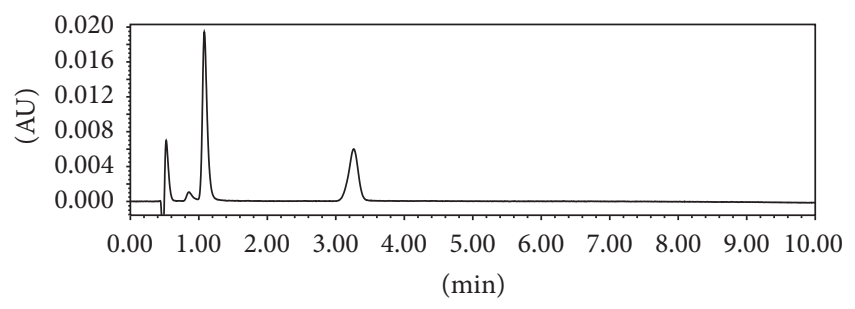

FiguRE 5: Chromatogram of acidic degradation.

acceptance criteria for $24 \mathrm{~h}$ at room temperature and $48 \mathrm{~h}$ at $3-5^{\circ} \mathrm{C}$ of temperature and after that the $\%$ assay was found to be less than $98 \%$ for both of the conditions.

3.2.2. Forced Degradation. The stability of pharmaceutical compounds in chemical and physical conditions is the most important study that correlates with its safety as well as efficacy. As per the ICH guideline, the stress study helps to determine the pathways of degradation and validate the stability indicating method for storage conditions [21]. The force degradation study of CMF and DCF was carried out by acid, base hydrolysis, oxidation, and photolytic and thermal degradation at room temperature.

In the acidic condition, the powdered equivalent weight of CMF and DCF was taken and $0.005 \mathrm{~N} \mathrm{HCl}$ was added then neutralized with $\mathrm{NaOH}$ and at $0 \mathrm{~h}$; it is found that both of the drugs are highly sensitive (Figure 5). $0.1 \mathrm{~N} \mathrm{NaOH}$ was used to provide alkaline condition (Figure 6). $3 \% \mathrm{H}_{2} \mathrm{O}_{2}$ was used for oxidative stress and it is found that drugs are stable up to $6 \mathrm{~h}$ (Figure 7). The powdered tablet of $\mathrm{CMF}$ and DCF was subjected to thermal degradation at $80^{\circ} \mathrm{C}$ for 3 hours. Moreover, it is found that CMF is thermal labile when compared to DCF. In photolytic condition drugs are directly exposed to day light, where CMF and DCF start degrading after $3 \mathrm{~h}$. All the detailed information regarding the force degradation study is given in Table 1 .

3.2.3. Specificity. The tests related to the interference of degraded product, mobile phase, diluents, and placebo were carried out for the specificity study; furthermore, it was confirmed during the stress degradation study by peak purity of CMF and DCF. From this study it was concluded that there is no interference of degraded product observed with pure drug peak of CMF and DCF and the peak purity chromatogram of both drugs is given in Figures 8(a) and 8(b). 


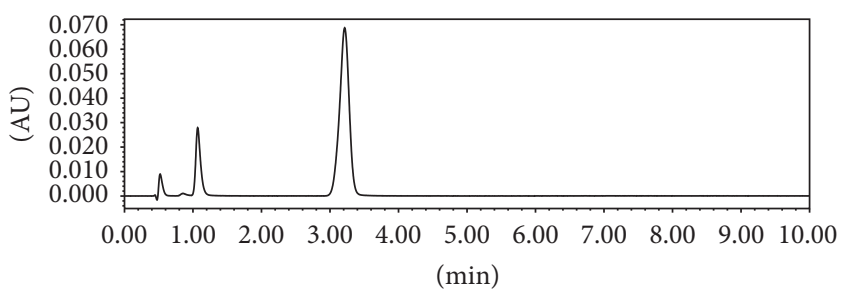

FIGURE 6: Chromatogram of alkaline degradation.

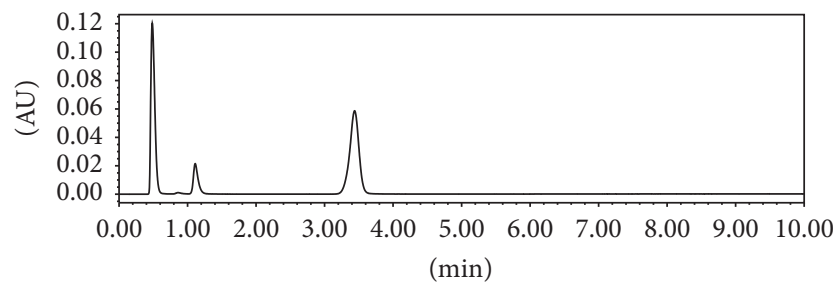

FIgURE 7: Chromatogram of oxidative degradation.

TABLE 1: Total degradation \% of CMF and DCF.

\begin{tabular}{lccc}
\hline \multirow{2}{*}{ Sr. no. } & \multirow{2}{*}{ Degradation condition } & \multicolumn{2}{c}{ Total degradation \% } \\
& & CMF & DCF \\
\hline 1 & Alkaline $(0.1 \mathrm{~N} \mathrm{NaOH}, 0 \mathrm{~h})$ & 19.33 & 4.46 \\
2 & Oxidative $\left(3 \% \mathrm{H}_{2} \mathrm{O}_{2}, 7 \mathrm{~h}\right)$ & 32.72 & 7.04 \\
3 & Thermal $\left(80^{\circ} \mathrm{C}, 3 \mathrm{~h}\right)$ & 40.12 & 4.03 \\
4 & Photolytic $(\mathrm{Day}$ light, $3 \mathrm{~h})$ & 21.93 & 0.5 \\
5 & Acidic $(0.005 \mathrm{~N} \mathrm{HCl}, 0 \mathrm{~h})$ & 45.23 & 92.59 \\
\hline
\end{tabular}

3.2.4. Accuracy. The accuracy study of CMF and DCF was carried out by testing three different percentages of test solution like 50,100 , and $150 \%$ by comparing the true concentration results with the measured concentration results. The $\%$ mean recovery of accuracy results of CMF and DCF was found between $99.49-100.05$ with $<2.0 \%$ of relative standard deviation (\% RSD) (Table 2).

3.2.5. Precision and Content Uniformity Test. The content uniformity study was carried out from the formulation of CMF and DCF tablet, and the \% assay was found between 98.58 and 100.21 for CMF and between 98.51 and 100.16 for DCF. The content of tablet was found uniform (Table 3).

3.2.6. Limit of Detection (LOD) and Limit of Quantification (LOQ). The study was finalized by comparing the signal to noise ratio $3: 1$ and $10: 1$ for LOD and LOQ, respectively. The LOD is $0.20 \mu \mathrm{g} / \mathrm{mL}$ and LOQ is $0.50 \mu \mathrm{g} / \mathrm{mL}$ for CMF and DCF.

3.2.7. Linearity. The linearity study was carried out for CMF and DCF in the range of 20.0 to $80.0 \mu \mathrm{g} / \mathrm{mL}$ for both of the drugs (Table 4$)$ and the linearity curve $x$-axis shows the concentration $(\mu \mathrm{g} / \mathrm{mL})$ while $y$-axis shows the peak area (absorbance unit) which indicates the method is linear and directly proportional to the concentration of drugs analytes in the sample solution (Figures 9(a) and 9(b)).

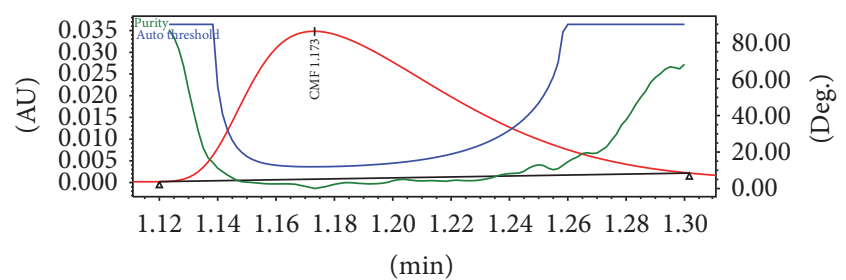

(a)

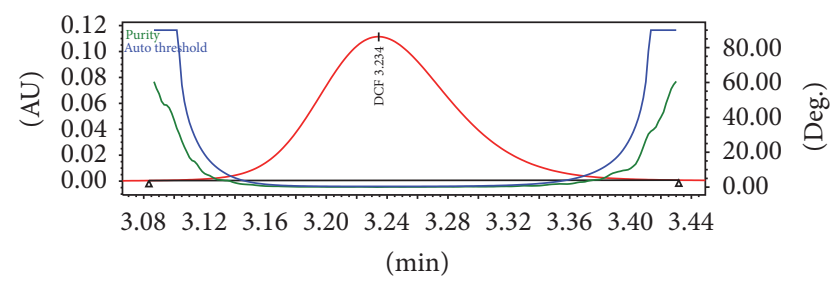

(b)

FIgure 8: (a) Peak purity chromatogram of CMF. (b) Peak purity chromatogram of DCF.

The results show that the peak intensity increase with concentration increases of analytes. That indicates the method is linear.

3.2.8. Robustness. The robustness study was carried out by small but deliberate changes like flow $( \pm 0.05 \mathrm{~mL} / \mathrm{min})$ and mobile phase composition $( \pm 0.5 \mathrm{~mL})$, with changes in $\mathrm{pH}$ $( \pm 0.2)$, wavelength $( \pm 5 \mathrm{~nm})$, column temperature $\left( \pm 2.0^{\circ} \mathrm{C}\right)$, and column lot. It is depicted from the results that the deliberate changes in chromatographic conditions do not affect the \% assay and retention time of the peak, drastically. The robustness study results are as per acceptance criteria which indicate the method is very robust.

3.2.9. System Suitability. The study related to system suitability was substantiated by tailing factor and resolution and number of theoretical plates of peaks for standard solution using both HPLC and UPLC method. So, the value of results obtained from both of the instruments is given in Table 5. For HPLC and UPLC the tailing factor is less than 2.0.

3.3. Application and Significance at HPLC to UPLC Method Transfer. The utilisation of the method is very unique, novel, and more beneficial which is a single method, for the simultaneous determination of three drugs using HPLC-UV and UPLC-PDA. The method was developed using HPLC for CMF, DCF, and PCM and then the method was transferred from high performance to ultraperformance, LC technique. In addition, the method is tested for the marketed tablet dosage forms of CMF and DCF (Anaspas) and CMF and PCM (Anafortan) according to the ICH Q2 (R1) guideline [18]. Then, the stability indicating method was validated for CMF and DCF using UPLC. The detailed force degradation study can be utilized to decide the better storage condition for both drugs. The chromatographs of test preparation from Anaspas and Anafortan tablets are given in Figures 10 and 11. Only $1.0 \mu \mathrm{L}$ of injection volume is sufficient for better peak absorbance at $220 \mathrm{~nm}$ of detection wavelength which shows 


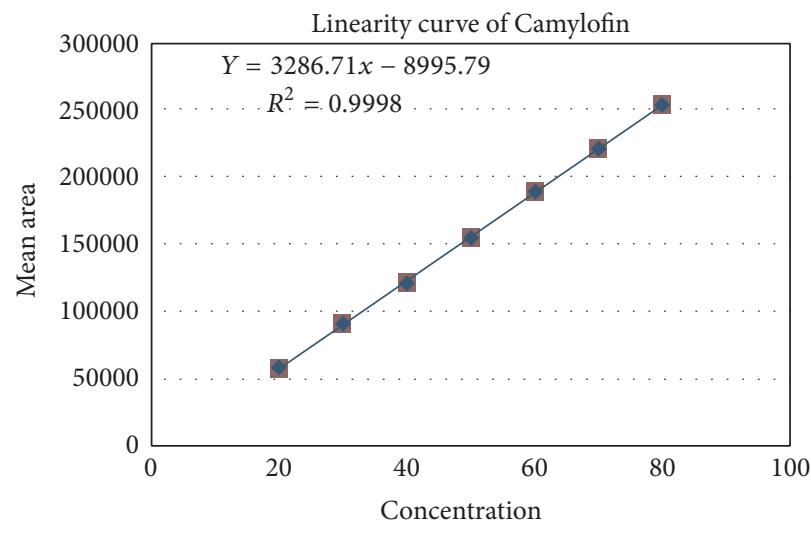

(a)

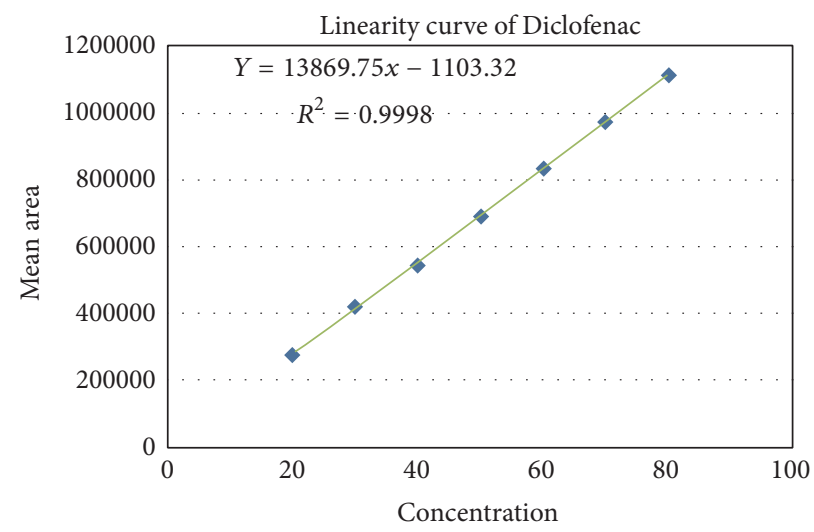

(b)

FIGURE 9: (a) Linearity curve of CMF and (b) linearity curve of DCF.

TABLE 2: Accuracy levels (\%) study results.

\begin{tabular}{|c|c|c|c|c|c|c|c|c|}
\hline Drugs & Level \% & Set no. & $\begin{array}{c}\text { Drug amount } \\
\text { added }(\mu \mathrm{g} / \mathrm{mL})\end{array}$ & $\begin{array}{l}\text { Drug amount } \\
\text { found }(\mu \mathrm{g} / \mathrm{mL})\end{array}$ & $\%$ recovery & $\%$ mean Recovery & $\% \mathrm{RSD}$ & $\begin{array}{c}\text { Mean of absolute \% } \\
\text { bias }\end{array}$ \\
\hline \multirow{9}{*}{$\mathrm{CMF}$} & \multirow{3}{*}{50} & 1 & 25.18 & 25.23 & 98.84 & \multirow{3}{*}{99.49} & \multirow{3}{*}{0.57} & \multirow{3}{*}{0.200} \\
\hline & & 2 & 24.78 & 24.86 & 99.70 & & & \\
\hline & & 3 & 25.62 & 25.64 & 99.92 & & & \\
\hline & \multirow{3}{*}{100} & 1 & 49.39 & 49.53 & 99.72 & \multirow{3}{*}{99.91} & \multirow{3}{*}{0.16} & \multirow{3}{*}{0.088} \\
\hline & & 2 & 49.61 & 49.60 & 100.01 & & & \\
\hline & & 3 & 49.57 & 49.57 & 99.99 & & & \\
\hline & \multirow{3}{*}{150} & 1 & 79.98 & 79.94 & 100.05 & \multirow{3}{*}{100.01} & \multirow{3}{*}{0.04} & \multirow{3}{*}{0.004} \\
\hline & & 2 & 80.49 & 80.52 & 99.97 & & & \\
\hline & & 3 & 81.02 & 81.02 & 100.01 & & & \\
\hline \multirow{9}{*}{ DCF } & \multirow{3}{*}{50} & 1 & 25.43 & 25.42 & 100.02 & \multirow{3}{*}{99.96} & \multirow{3}{*}{0.17} & \multirow{3}{*}{0.027} \\
\hline & & 2 & 25.47 & 25.44 & 100.10 & & & \\
\hline & & 3 & 25.18 & 25.24 & 99.77 & & & \\
\hline & \multirow{3}{*}{100} & 1 & 49.57 & 49.58 & 99.99 & \multirow{3}{*}{99.99} & \multirow{3}{*}{0.06} & \multirow{3}{*}{0.007} \\
\hline & & 2 & 49.54 & 49.57 & 99.94 & & & \\
\hline & & 3 & 49.61 & 49.58 & 100.05 & & & \\
\hline & \multirow{3}{*}{150} & 1 & 74.88 & 74.86 & 100.01 & \multirow{3}{*}{100.05} & \multirow{3}{*}{0.09} & \multirow{3}{*}{0.053} \\
\hline & & 2 & 75.10 & 74.99 & 100.15 & & & \\
\hline & & 3 & 74.94 & 74.95 & 99.99 & & & \\
\hline
\end{tabular}

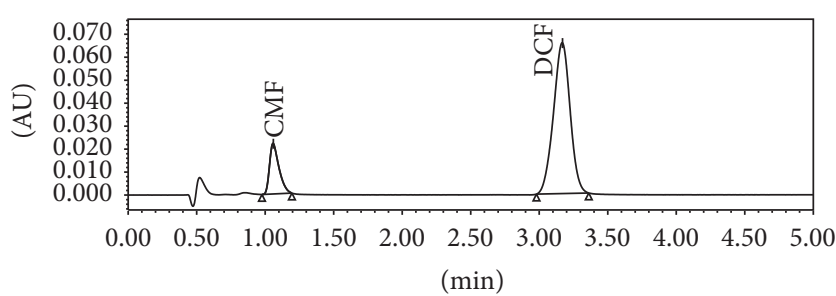

Figure 10: Chromatogram of CMF and DCF (50:50 $\mu \mathrm{g} / \mathrm{mL}$; Anaspas tablet).

the high throughput analysis. The proposed method can be also useful for individual drug substances and products.

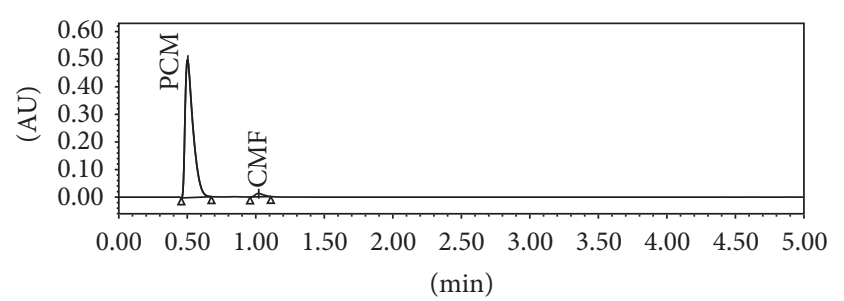

Figure 11: Chromatogram of PCM and CMF $(300: 25 \mu \mathrm{g} / \mathrm{mL}$; Anafortan tablet).

UPLC works faster as runtime and decreases four times compared to HPLC, approximately sixteen times less solvent consumption compared with flow rate, and analysis decreases 
TABLE 3: Content uniformity study results.

\begin{tabular}{|c|c|c|c|c|}
\hline \multirow{4}{*}{ Sets } & \multicolumn{4}{|c|}{ Content uniformity study } \\
\hline & \multirow{2}{*}{\multicolumn{2}{|c|}{$\begin{array}{c}\text { Method precision } \\
\text { \% assay }\end{array}$}} & \multirow{2}{*}{\multicolumn{2}{|c|}{$\begin{array}{c}\text { Intermediate } \\
\text { precision } \\
\% \text { assay }\end{array}$}} \\
\hline & & & & \\
\hline & $\mathrm{CMF}$ & DCF & $\mathrm{CMF}$ & DCF \\
\hline Set 1 & 99.27 & 99.26 & 99.35 & 100.14 \\
\hline Set 2 & 99.03 & 98.51 & 100.18 & 99.81 \\
\hline Set 3 & 98.98 & 99.71 & 99.92 & 100.16 \\
\hline Set 4 & 98.99 & 98.89 & 98.88 & 99.11 \\
\hline Set 5 & 99.02 & 98.58 & 98.94 & 99.15 \\
\hline Set 6 & 98.58 & 100.07 & 99.84 & 99.79 \\
\hline Set 7 & 100.13 & 99.33 & 98.94 & 100.07 \\
\hline Set 8 & 99.44 & 100.02 & 98.87 & 99.99 \\
\hline Set 9 & 99.60 & 98.64 & 100.04 & 99.87 \\
\hline Set 10 & 100.21 & 99.77 & 99.19 & 98.79 \\
\hline Mean of \% assay & 99.33 & 99.28 & 99.42 & 99.69 \\
\hline$\% \mathrm{RSD}$ & 0.53 & 0.60 & 0.53 & 0.49 \\
\hline $\begin{array}{l}\text { Mean of absolute \% } \\
\text { bias }\end{array}$ & 0.328 & 1.306 & 0.419 & 1.722 \\
\hline
\end{tabular}

TABLE 4: Linearity study results.

\begin{tabular}{lcc}
\hline Parameters & \multicolumn{2}{c}{ Samples } \\
\hline Slope & 3286.71 & DCF \\
Standard error of slope & 22.32 & 13869.75 \\
Intercept & -8995.79 & 98.01 \\
Standard error of intercept & 1202.01 & -1103.32 \\
Regression coefficient & 0.9998 & 5278.29 \\
\hline
\end{tabular}

TABLE 5: System suitability results.

\begin{tabular}{lcc}
\hline System suitability parameter & \multicolumn{2}{c}{$\% \mathrm{RSD}^{\mathrm{a}}\left(\mathrm{NMT}^{\mathrm{b}} 2.0\right)$} \\
\hline Validation parameters & Drugs \\
& $\mathrm{CMF}$ & $\mathrm{DCF}$ \\
\hline Solution stability & 0.24 & 0.86 \\
Specificity & 0.32 & 1.05 \\
Limit of quantification & 0.38 & 0.15 \\
Linearity & 0.77 & 0.23 \\
Method precision & 0.61 & 0.53 \\
Intermediate precision & 0.41 & 1.10 \\
Accuracy & 0.12 & 0.10 \\
Robustness & 0.53 & 0.17 \\
\hline
\end{tabular}

${ }^{a}$ Relative standard deviation.

${ }^{\mathrm{b}}$ Not more than.

up to four times. Thus, the provided method is very beneficial according to higher work efficiency of UPLC compared to HPLC. Overall, we can say it is a faster, economically cheap, environmentally green, and user friendly technology (Table 6).
TABLE 6: Significant values in comparison with UPLC and HPLC.

\begin{tabular}{|c|c|c|c|}
\hline \multirow{2}{*}{ Sr. no. } & \multirow{2}{*}{. Chromatographic conditions } & \multicolumn{2}{|c|}{ Instrumentation } \\
\hline & & UPLC & HPLC \\
\hline 1 & Flow $(\mathrm{mL} / \mathrm{min})$ & $0.250^{*}$ & 1.0 \\
\hline 2 & Injection volume $(\mu \mathrm{L})$ & $1.0^{*}$ & 20.0 \\
\hline 3 & Amount loaded on column $(\mu \mathrm{g})$ & $0.05^{*}$ & 1.00 \\
\hline 4 & Run time (min) & $5.0^{*}$ & 20.0 \\
\hline 5 & Drugs & CMF DCF & CMF DCF \\
\hline 6 & Tailing factor $\left(T_{f}\right)$ & 1.4830 .956 & $1.33 \quad 1.34$ \\
\hline 7 & Resolution $\left(R_{s}\right)$ & 11.87 & 25.90 \\
\hline 8 & Retention time (min) & $1.1 \quad 3.2$ & $2.6 \quad 13.7$ \\
\hline 9 & Theoretical plates $(N)$ & 3296 & $2678 \quad 7534$ \\
\hline
\end{tabular}

\section{Conclusion}

This single method is very appreciative for separation of three drugs together using two different instruments with same chromatographic conditions. The validated stability indicating chromatographic method for the combination dosage, Anaspas, is also useful to decide the storage condition and its percentage degradation during storage. Moreover, it is transferred from HPLC to UPLC to avoid extra solvent consumption. The faster analysis provides high precision and sensitivity for the better work efficiency. The UPLC method offers shorter analysis time, column equilibrium time, and system start up time which decreases the extra labour and time of routine quality control. The results of all the analytical method validation parameters were found within the acceptance limit of the ICH guidelines.

\section{Competing Interests}

The authors declare that there is no conflict of interests regarding the publication of this paper.

\section{Acknowledgments}

The authors are very grateful to the Hetero drugs Limited (Hyderabad, India) for the gifted reference standard of Paracetamol, while CMF and diclofenac potassium were purchased from the Sigma Aldrich. Special thanks are due to Rajiv Gandhi National Fellowship (UGC, New Delhi) for financial support and Center of Excellence in Drug Discovery, NFDD Complex Department of Chemistry, Saurashtra University, Rajkot (Gujarat, India), for providing instrumental facilities, supported by DPRP, Industries Commissionerate (GoG), and Saurashtra University, Rajkot (UGC-SAP sponsored and DST-FIST and DSR funded).

\section{References}

[1] Sweetman and C. Sean, Martindale, The Complete Drug Reference, 36th edition, 2009.

[2] F. A. Elbarbry, M. M. Mabrouk, and M. A. El-Dway, "Determination of the analgesic components of Spasmomigraine tablet by liquid chromatography with ultraviolet detection," Journal of AOAC International, vol. 90, pp. 94-101, 2007. 
[3] M. J. O’Neil, A. Smith, P. E. Heckelman, J. R. Obenchain Jr., A. R. Gallipeau, and M. Ann D'Arecca, The Merck Index: An Encyclopedia of Chemicals, Drugs, and Biological, Merck, Rahway, NJ, USA, 13th edition, 2001.

[4] N. M. Davies and K. E. Anderson, "Clinical pharmacokinetics of diclofenac. Therapeutic insights and pitfalls," Clinical Pharmacokinetics, vol. 33, no. 3, pp. 184-213, 1997.

[5] C. Dollery, Therapeutic Drugs, Churchill Livingstone, Edinburgh, Scotland, 2nd edition, 1999.

[6] S. C. Sweetman, The Martindale: The Complete Drug Reference, Pharmaceutical Press, London, UK, 35th edition, 2006.

[7] L. B. Laurence and J. S. Lozo, "Analgesics, antipyretic and antiinflammatory agents," in Goodman \& Gilman's the Pharmacological Basis of Therapeutics, pp. 671-675, Medical Publishing, Division, New York, NY, USA, 11th edition, 2006.

[8] S. Budavari, Ed., The Merck Index: An Encyclopedia of Chemicals, Drugs, and Biologicals, Merck and Co., Inc, White House Station, NJ, USA, 2001.

[9] United States Pharmacopeia, National Formulary 25, United States Pharmacopeia, Rockville, Md, USA, 2007.

[10] A. Jawad, Hepatology and Transplant Hepatology: A Case Based Approach, Springer Science \& Business Media, New York, NY, USA, 2010.

[11] Acetaminophen, The American Society of Health-System Pharmacists, http://www.drugs.com/monograph/acetaminophen.html.

[12] S. Makwana, M. Patel, B. Singh, J. Upadhyay, and A. Shah, "Development and validation of a stability indicating RP-UPLC method for the determination of Paracetamol and Ibuprofen in tablet," Journal of Chemical and Pharmaceutical Research, vol. 7, no. 4, pp. 1308-1315, 2015.

[13] R. R. Singh, M. V. Rathnam, S. J. Singh, and R. V. K. Vegesna, "A stability indicating gc-fid method for camylofin dihydrochloride and diclofenac potassium in pharmaceutical preparation," International Journal of Pharmacy and Pharmaceutical Sciences, vol. 4, no. 1, pp. 317-324, 2012.

[14] N. N. Kadam, P. C. Patil, and R. R. Singh, "A stability-indicating RP-HPLC determination of camylofin dihydrochloride in drug substance," International Journal of Pharmacy and Pharmaceutical Sciences, vol. 3, no. 3, pp. 153-158, 2011.

[15] N. S. Patel, V. P. Gandh, R. S. Mehta, and K. K. Bhatt, "Application of HPLC and HPTLC-densitometry for the simultaneous determination of camylofin and diclofenac in pharmaceutical dosage form," Der Pharmacia Lettre, vol. 2, no. 5, pp. 193-207, 2010.

[16] R. R. Singh, M. V. Rathnam, and R. Vegesna, "Simultaneous RP HPLC determination of Camylofin dihydrochloride and paracetamol in pharmaceutical preparations," TSI Journal, vol. 7, no. 11, 2008.

[17] B. Anupama and V. Ramakrishna, "New visible spectrophotometric methods for determination of camylofin," International Journal of Research in Pharmacy and Chemistry, vol. 2, no. 4, pp. 1020-1022, 2012.

[18] ICH Guideline, Q2 (R1) Step 4, Validation of Analytical Procedures: Text and Methodology, 2005.

[19] USP, United States Pharmacopoeia, United States Pharmacopeial Convention, Rockville, Md, USA, 30th edition, 2007.

[20] AOAC Peer-Verified Methods Program, Manual on Policies and Procedures, AOAC International, Arlington, Va, USA, 1998.

[21] ICH Guidelines, "Q1A (R2): stability testing of new drug substances and products (revision 2)," in Proceedings of the
International Conference on Harmonization, November 2003, http://www.fda.gov/downloads/drugs/guidancecomplianceregulatoryinformation/guidances/ucm073369.pdf. 

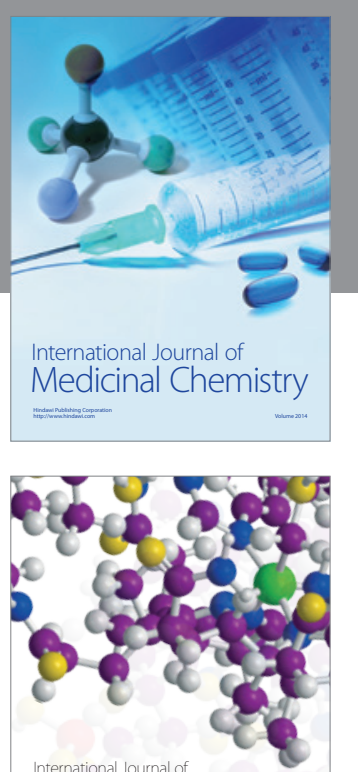

Carbohydrate Chemistry

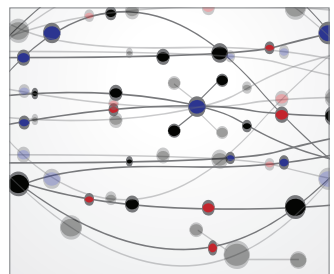

The Scientific World Journal
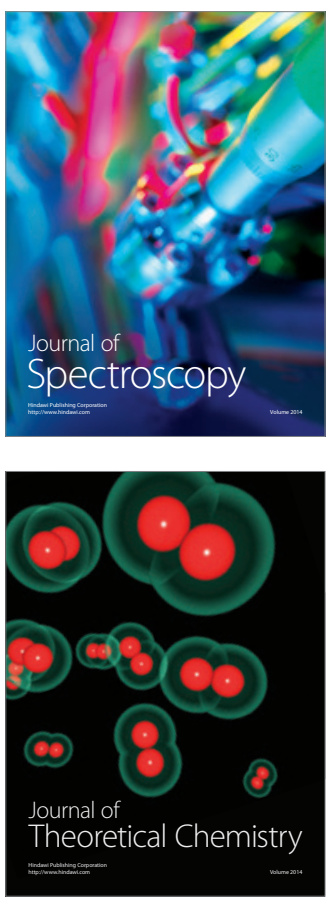
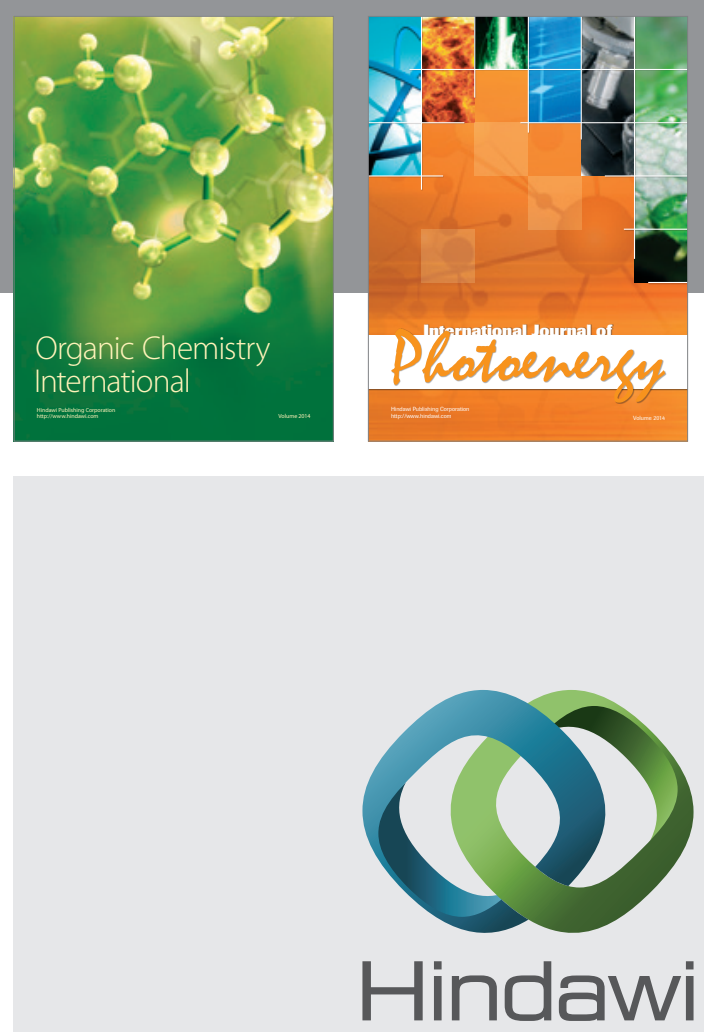

Submit your manuscripts at

http://www.hindawi.com

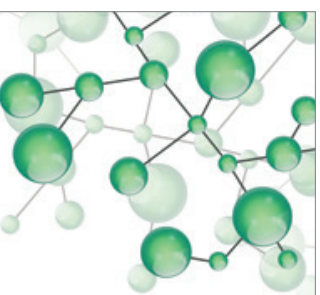

International Journal of

Inorganic Chemistry

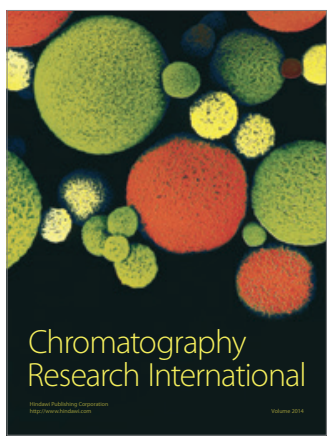

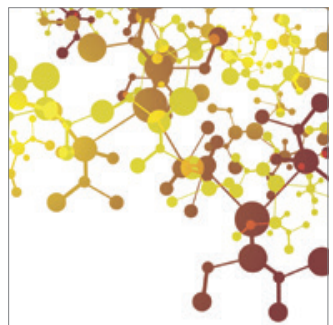

Applied Chemistry
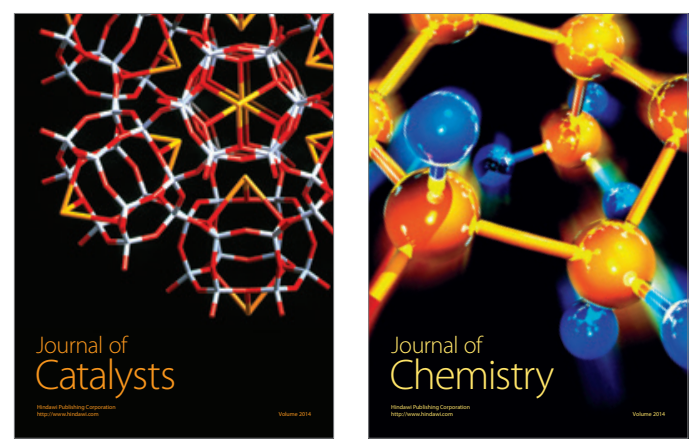
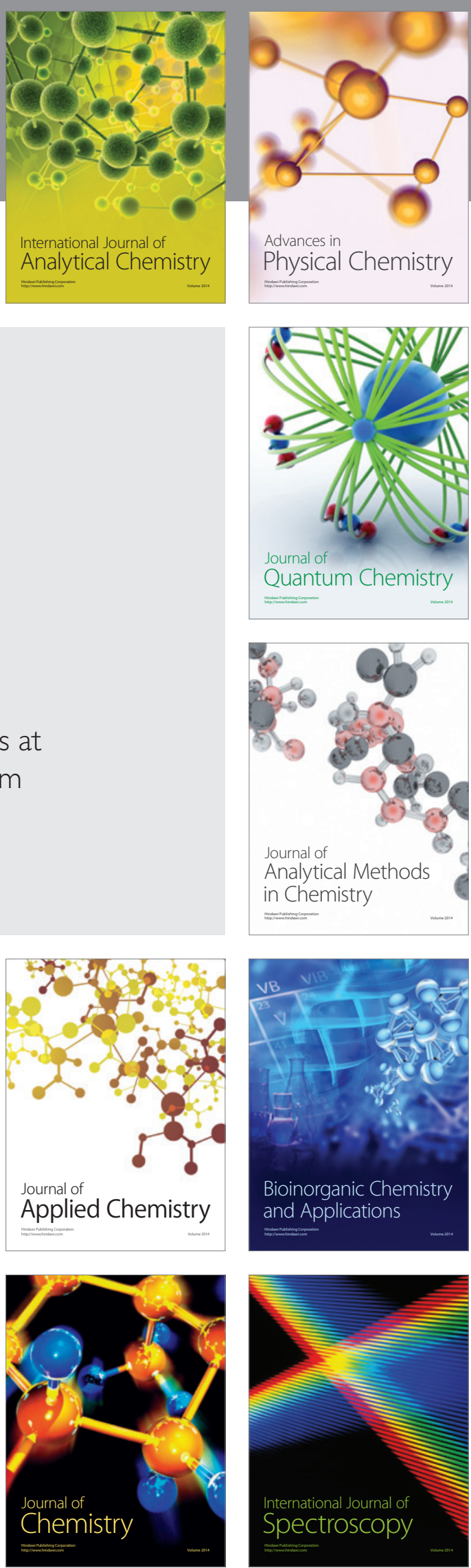